\title{
Factors Associated With Burnout Among Nurses at International Hospital Kampala (IHK)
}

\author{
Ashaba Aheebwa Anita ${ }^{1} \&$ Omona Kizito ${ }^{1}$ \\ ${ }^{1}$ Faculty of Health Sciences, Uganda Martyrs University, Uganda \\ Correspondence: Omona Kizito, Professor, Faculty of Health Sciences, Uganda Martyrs University, Uganda. Tel: \\ 256-706-464-873.
}

Received: November 8, 2020

Accepted: December 28, 2020

Online Published: December 31, 2020

doi:10.20849/ijsn.v5i4.840

URL: https://doi.org/10.20849/ijsn.v5i4.840

\begin{abstract}
Introduction: Burnout is a psychological syndrome involving physical depletion, feelings of helplessness, negative self-concept, and negative attitudes towards work, life, and others. Burnout is a problem among health care professionals and nurses are found to be vulnerable. It is associated with a decrease in occupational well-being and increase in absenteeism, turnover and illness.

Objectives: To evaluate the prevalence and factors associated with burnout among nurses at International Hospital Kampala (IHK).

Methods: Analytical cross-sectional design was used. Data was collected from a sample of 120 nurses using questionnaire and Maslach Burnout Inventory (MBI) tools. Analysis was done using Statistical Package for Social Sciences and Microsoft excel.

Results: The prevalence of burnout within the MBI subscales was highest in the subscale of personal accomplishment (PA) - 72.5\%), followed by Depersonalization (DP) - 66.8\% and Emotional Exhaustion (EE) $61.7 \%$. Overall prevalence of burnout among was $66.95 \%$. Nurses with high burnout had the lowest level of personal accomplishment-18.33\% while nurses with low burnout had the highest level of personal accomplishment-72.5\% . Age $\left(\mathrm{X}_{(2)}^{2}=6.670, \mathrm{p}=0.036\right)$ was associated with burnout. Respondent years in service was more highly associated with burnout $\left(\mathrm{X}^{2}{ }_{(2)}=10.961, \mathrm{p}=0.004\right)$. Job satisfaction $\left(\mathrm{X}^{2}{ }_{(1)}=4.361, \mathrm{p}=0.037\right)$ was associated with burnout. Emotional Exhaustion (EE) of the respondents $\left(X_{(2)}^{2}=29.197, p=0.000\right)$ was associated with burnout. Many nurses, 61(50.8\%) had EE and burnout. Depersonalization (DP) $\left(\mathrm{X}_{(2)}^{2}=72.803, \mathrm{p}=0.000\right)$ was also associated with burnout. Hours worked in a day $\left(\mathrm{X}_{(1)}^{2}=72.803, \mathrm{p}=0.016\right)$ was associated with burnout. Getting social support at work $\left(\mathrm{X}_{(1)}^{2}=72.803, \mathrm{p}=0.016\right)$ was associated with burnout, thus $48(40.0 \%)$ of the nurses who got social support had burnout.
\end{abstract}

Conclusion: The prevalence of burnout is quite high among nurses.

Keywords: burnout, Emotional Exhaustion (EE), Depersonalization (DP), Personal Accomplishment (PA), Maslach Burnout Inventory (MBI)

\section{Introduction}

\subsection{Background to the Study}

Maslach and Jackson (1981) defined burnout as a psychological syndrome involving physical depletion, feelings of helplessness, negative self-concept, and negative attitudes towards work, life, and others. In line with Maslach and Jackson's (1981) definition of burnout, the Maslach Burnout Inventory (MBI) measures burnout across three dimensions: emotional exhaustion (EE), depersonalization (DP), and personal accomplishment (PA). The MBI is referred to as the 'gold standard' for measuring burnout in empirical research (Helen, et al., 2017).

In many studies, burnout is usually measured across three dimensions. These are emotional exhaustion (EE), depersonalization (DP) and reduced personal accomplishment (PA) (Maslach, Jackson, \& Leiter, 1996). Emotional exhaustion (EE) is defined as a lack of energy and interest in one's work due to the experience of drained emotional resources by the person. Depersonalization (DP) or cynicism presents itself in impassive attitudes and thoughts and acts as a protection from exhaustion by making a person distance himself or herself from others. Lastly, a lack of personal accomplishment (PA) or self-efficacy is the feelings of diminished 
efficacy, competence and achievement at work. A high level of emotional exhaustion (EE), high level of depersonalization (DP) and a reduced sense of personal accomplishment (PA) is typically characteristic of professionals with a high degree of burnout (Heeb \& Haberey-Knuessi, 2014).

Burnout (BO) is a problem among health care professionals and nurses are found to be more vulnerable. It is associated with a decrease in occupational well-being and an increase in absenteeism, turnover and illness (Jef, et al., 2015). It can be regarded as a major public health problem and a cause of concern for health care policymakers (Ester, et al., 2010).

Burnout has been associated with various forms of job withdrawal absenteeism, intention to leave the job, and actual turnover. However, for people who stay on the job, burnout leads to lower productivity and effectiveness at work. Consequently, it is associated with decreased job satisfaction and a reduced commitment to the job or the organization (Maslach and Leiter, 2016). This syndrome of emotional exhaustion, depersonalization and low personal accomplishment culminates in decreased effectiveness at work. This is evidenced with a number of professions that heavily involve human interactions such as physicians, nurses, and educators. Burnout is associated with decreased job performance and reduced job commitment and predicts stress-related health problems and low career satisfaction (Jawad et al., 2016).

A systematic review and meta-analysis conducted to examine burnout symptoms prevalence in nurses worldwide showed that the overall prevalence of burnout symptoms among global nurses was $11.23 \%$. The highest burnout symptoms prevalence was in Sub-Saharan African region while Europe and Central Asia region had the lowest (Tiffany, 2019). In another study, the overall burnout rate was 67\%. In the multivariate analysis, notable factors associated with burnout included inadequate operating room exposure (OR 7.57, $\mathrm{p}=0.011$ ), hostile faculty (OR 4.07, $\mathrm{p}=0.008$ ), and social stressors outside of work (OR 4.52, $\mathrm{p}=0.008)$. Meaningful mentorship was protective against burnout in the multivariate regression models (OR $0.338, \mathrm{p}=0.031$ ) (Attenello, et al., 2018)

In Spain, the burnout syndrome is beginning to be regarded as an occupational illness of high prevalence among nursing. Individuals suffering from the syndrome manifest important health problems. The prevalence of burnout among nursing professionals is high. Gender, age, marital status, level of healthcare, work shift and healthcare service areas predicted at least one of the dimensions of the syndrome (Guillermo, et al., 2015).

A study done in Taiwan by Li-Ping, et al., (2014) showed that physician assistant is an emerging high burnout group; its severity is similar to that of nurses and far more than that of physicians, administrative staff and medical technicians. These findings may contribute to the development of feasible strategies to reduce the stress which results in the burnout currently plaguing most hospitals.

Prevalence of burnout among physicians, nurses, and healthcare providers in Sub-Saharan Africa ranges from 40 to $80 \%$. The highest levels of burnout were recorded among nurses although all health care providers reported high levels of burnout. High levels of burnout were associated with unfavorable work conditions, high job demands, and low job satisfaction (Dubale, et al., 2019).

A study done in Uganda established that $63.08 \%$ of nurses had high burnout (Martha, 2012). However, there is limited information regarding burnout in Uganda and International Hospital Kampala in particular. With grave impact on work productivity, patient care, staff attrition and turnover rates, a better understanding of existing relationships between burnout and general health of nurses is required.

The Director of Nursing at International Hospital Kampala (IHK) stated in the new vision paper that, in Uganda nurses experience burnout due to long working hours, unfavorable working environments, and others. The work environments include inadequate work equipment for nurses and poor pay. He also explained that nurses play a big role in a patient's recovery from both a physical and emotional perspective (Jacky, 2019). It is against this background that this research is going to carry out a study about factors associated with burnout among nurses at International Hospital Kampala.

\subsection{Study Area}

The area of study was International Hospital Kampala (IHK). The hospital is located in Namuwongo, Makindye division, in Southeast Kampala. The different departments in which services are offered at IHK include; accident and emergency, out-patient, children center, specialist center, theatre, intensive care, pediatrics, in patient (maternity), and inpatient (medical-surgical). The nurses that work in those departments follow the 12-hour shift schedules that are either fixed day shifts or rotating shifts between day and night shifts. The hospital has a total of about 170 nurses. 


\subsection{Conceptual Framework}

The conceptual framework below shows the relationship between the different independent variables and burnout which is the dependent variable. The independent variables include individual factors and organizational factors that are associated with burnout. Individual factors and socio-demographic factors play an important role among factors responsible for developing burnout (Anna, et al., 2018). Job satisfaction is significantly associated with burnout (Ozlem, et al., 2016). Burnout has positive correlation with workload and an increase in workload leads to increase in burnout (Mansour, et al., 2015). Poor work environment contributed significantly to burnout in hospital nurses and is potentially a significant cost to the hospital recruiting new staff due to high turnover rate caused by burnout(Priscilla, et al., 2015).

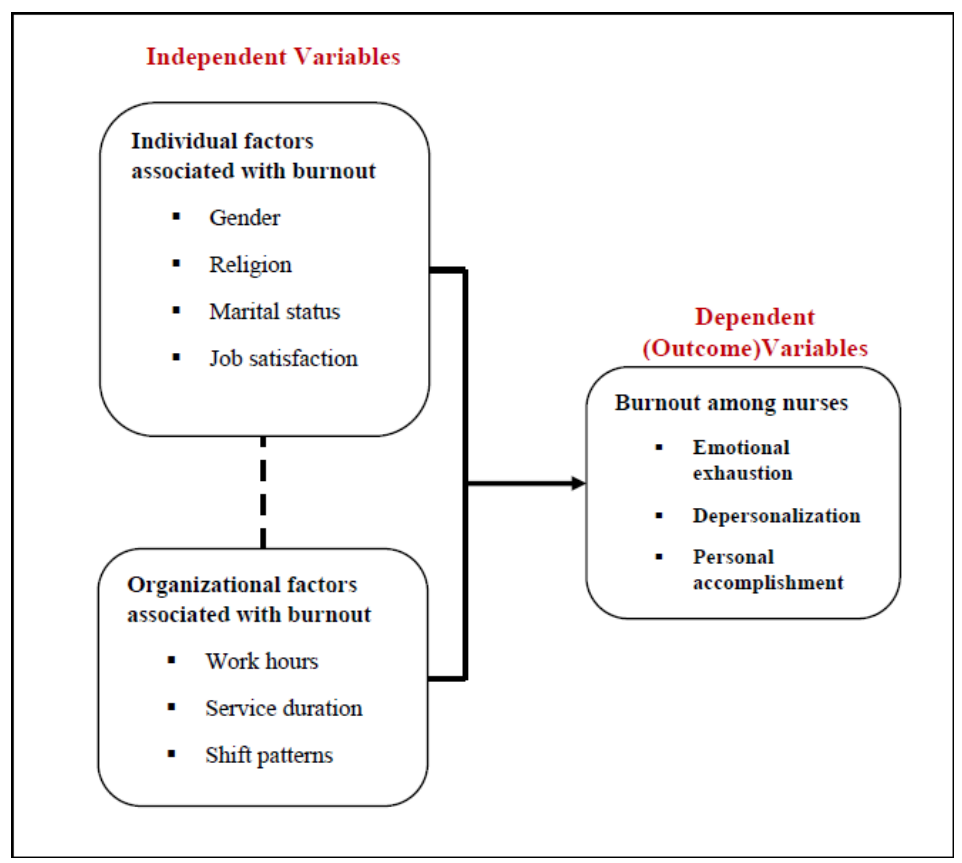

Figure 1. Conceptual framework for burnout

\subsection{Objectives of the Study}

The study had the following specific objectives

1. To determine the prevalence of burnout among nurses in International Hospital Kampala.

2. To establish the distribution of Personal Accomplishment (PA) among nurses with burnout in International Hospital Kampala

3. To determine the individual factors associated with burnout among nurses in International Hospital Kampala.

4. To determine the organizational factors associated with burnout among nurses in International Hospital Kampala.

\section{Methods}

\subsection{Study Area}

The area of study was International Hospital Kampala. See details in section 1.2 of this manuscript.

\subsection{Study Design}

The researcher used analytical cross-sectional study design in which quantitative strategies of data collection were used. Using this study design, the researcher was able to assess the factors associated with burnout among nurses at International Hospital Kampala.

\subsection{Study Population}

The study population was the nurses at International Hospital Kampala. 


\subsection{Study Unit}

The study unit was a nurse, who consented and satisfied the eligibility criteria and was working in the hospital between May and June, 2019.

\subsection{Inclusion and Exclusion Criteria}

The inclusion criteria were individuals who were available during the study period and had consented to take part in the study. They must have been working in the hospital between May and June 2019. The exclusion criteria were individuals who were on leave within the said time frame.

\subsection{Sample Size}

Sample size was calculated using Taro Yamane formula (Yamane, 1973) and it was representative of the target population. This formula is used to calculate a sample size for a population whose size is known. The number of nurses at International Hospital Kampala is known, hence making this method appropriate for calculating the sample size for the study.

$$
\text { Sample size }(n)=\frac{\mathrm{N}}{\left[1+\mathrm{N}\left(e^{2}\right)\right]}
$$

Where $\mathrm{N}$ stands for the population size of nurses at IHK $=170$

$\mathrm{e}$ is the error level $=0.05$

Confidence interval $=95 \%$

$$
\text { Sample size }=\frac{170}{\left[1+170\left(0.05^{2}\right)\right]}=\frac{170}{1.425}=119.3
$$

Sample size $=119.30$

Sample size $=120$

\subsection{Sampling Technique}

The study employed simple random sampling method and used probability proportionate to size to identify the number of nurses from each department. The researcher was convinced that the target population was not uniform. This is because different departments may not necessarily have similar characteristics, since the nurses within these departments may not always be subjected to the same stressors on their job. Simple random sampling technique was, therefore, used to ensure that each sub-group was represented in the sample in a proportion equivalent to its size in the population. IHK has a total of 8 departments that include; accident and emergency and outpatient (A/E and OPD), intensive care unit (ICU), specialist center (SC), children center (CC), inpatient department 1 (IPD 1) or maternity ward, inpatient department 2 (IPD 2) or medical-surgical ward, theatre and pediatrics ward. Below (table 1) is a summary of the departments at IHK, their proportion, and the study units that were selected to make the sample size.

Table 1. Proportionate sample from respective departments at IHK

\begin{tabular}{llllllllll}
\hline Departments & A/E \& OPD & ICU & SC & CC & IPD1 & Theatre & IPD2 & Pead & $\begin{array}{l}\text { Grand Total } \\
\text { Number }\end{array}$ \\
\hline Number of staff & 20 & 26 & 6 & 8 & 44 & 28 & 26 & 12 & $\mathbf{1 7 0}$ \\
\hline $\begin{array}{l}\text { Samples per } \\
\text { department }\end{array}$ & 14 & 18 & 4 & 6 & 31 & 20 & 18 & 9 & $\mathbf{1 2 0}$ \\
\hline
\end{tabular}

\subsection{Study Variables}

The independent variables in this study were individual and organizational factors associated with burnout among nurses at IHK. These were; age, gender, department and years in service of the respondents and job satisfaction, among others.

The dependent variable was burnout among nurses at IHK, sub-categorized as Emotional Exhaustion (EE), Depersonalization (DP) and Personal Accomplishment (PA). 


\subsection{Data Collection Tools and Techniques}

Study used Maslach Burnout Inventory (MBI) tool and Questionnaires.

\subsubsection{The Maslach Burnout Inventory (MBI) Tool}

The Maslach Burnout Inventory (MBI) (Maslach and Jackson, 1981;Ergin, 1992) consists of 22 self-descriptive statements which measure three aspects of burnout: emotional exhaustion (EE), depersonalization (DP) and decreased personal accomplishment (PA). Items are rated on a 7-point Likert scale ranging from 0 (never) to 6 (every day) (Funda, et al., 2017).A high degree of burnout is reflected in a combination of high scores on EE and DP and low scores on PA. The distribution of items in three sub-scales of burnout is shown in Table 2 below.

Table 2. Distribution of test items in the 3 sub-scales of the MBI

\begin{tabular}{lll}
\hline Dimensions of MBI & $\begin{array}{l}\text { Test item numbers in the MBI tool (Total } \\
\text { 2 22questions) }\end{array}$ & $\begin{array}{l}\text { Total Number of questions Per } \\
\text { Dimension }\end{array}$ \\
\hline EE & $1,2,3,6,8,13,14,16,20$ & 9 \\
\hline DP & $5,10,11,15,22$ & 5 \\
\hline PA & $4,7,9,12,17,18,19,21$ & 8 \\
\hline
\end{tabular}

The scoring pattern on each item is on a seven-point continuum from 'never', 'a few times a year or less', 'once a month or less', 'a few times a month', 'once a week', 'a few times a week' to 'every day' and the frequency on this continuum is reflected through $0,1,2,3,4,5$ and 6 respectively.

The possible range of scores on EE, DP and PA is 0-54, 0-30 and 0-48 in that respective order. MBI tool is both highly reliable and valid, as a measure of burnout (Lusine et al., 2010).Individuals with burnout have a score of 27 and above in EE, 10 and above in DP, 40 and above in PA as summarized in table 3 below.

Table 3. MBI subscale cut-off scores and categories for burnout

\begin{tabular}{lll}
\hline S. No & Subscale \& Category Under Each Subscale & Cut-off Scores \\
\hline $\mathbf{0 1}$ & EE (Score: 0 - 54) & $\geq 27$ \\
& - High & $19-26$ \\
& - $\quad$ Moderate & $0-18$ \\
& - Low & $\geq 10$ \\
\hline $\mathbf{0 2}$ & DP (Score: 0 - 30) & $6-9$ \\
& - High & $0-5$ \\
& - Moderate & \\
& - Low & $0-33$ \\
\hline $\mathbf{0 3}$ & PA (Score: 0 - 48) & $34-39$ \\
& - High & $\geq 40$
\end{tabular}

$\overline{\mathrm{EE}}=$ Emotional Exhaustion, $\mathrm{DP}=$ Depersonalization, $\mathrm{PA}=$ reduced Personal Accomplishment (Viva et al., 2011).

\subsubsection{Questionnaire}

Quantitative data was collected via self-administered questionnaires adopted to include an existing MBI tool, developed in the study of burnout. The questionnaire was structured with closed-ended questions. It included four sections that were A, B, C, and D. Section A included socio-demographic information, section B assessed the first research question, $\mathrm{C}$ assessed the second, and $\mathrm{D}$ assessed the third. 


\subsection{Data Entry, Analysis and Presentation}

The MBI was used to measure burnout according to the three subscales: emotional exhaustion (nine items), depersonalization (five items), and personal accomplishment (eight items). High levels of burnout were indicated by high scores of emotional exhaustion and depersonalization and low scores (reverse scoring) of personal accomplishment. Each item was scored from 0 (never) to 6 (everyday). MBI subscale scores were determined for each of the respondents using the total of scores for the items under the subscales.

Quantitative data such as; age, sex, department, years in practice, job satisfaction, hours, days, clients, work, conflict, information, severity, support, feedback and decisions from a folder copy was entered in Excel sheet and imported to Stata version 13 and further analysis. Univariate, bivariate and multivariate analysis was done as appropriate (Barros and Hirakata, 2003).

\subsection{Quality Control}

The researcher ensured quality results by following the inclusion and exclusion criteria of the study. The researcher also ensured confidentiality and proper data management and storage after data collection. The researcher checked the questionnaires for accuracy and completeness.

\subsection{Ethical Considerations}

Ethical approval was sought and granted the Institutional Review Board (IRB) of the hospital. Participants consented before taking part in the study. Confidentiality of the participant's information was maintained as they were not to include their names on the data collection tools.

\section{Results}

\subsection{Socio-demographic Characteristics of Respondents}

The socio-demographic characteristics included; age, sex, department, and years in practice. Majority (77.5\%) of the participants had the age of 26 to 35 years and most (88.33\%) of them were females. Majority $(25.83 \%)$ of the participants were working in the Inpatient department (IPD 1/maternity ward) and most (45.0\%) of the participants had been in practice for a period of 2 to 5 years as shown in Table 4 below.

Table 4. Socio-demographic characteristics of respondents

\begin{tabular}{|c|c|c|c|}
\hline S. No & Variables & Frequency $(n=120)$ & Percentage (\%) \\
\hline \multirow[t]{4}{*}{01} & Age & & \\
\hline & - $\quad 18$ to 25 years & 11 & 9.2 \\
\hline & - 26 to 35 years & 93 & 77.5 \\
\hline & - $\quad \geq 36$ years & 16 & 13.3 \\
\hline \multirow[t]{3}{*}{02} & Gender & & \\
\hline & - $\quad$ Male & 14 & 11.7 \\
\hline & - $\quad$ Female & 106 & 88.3 \\
\hline \multirow[t]{9}{*}{03} & Department & & \\
\hline & - Theatre & 20 & 16.7 \\
\hline & - $\quad$ Pediatrics & 8 & 6.7 \\
\hline & - $\quad$ IPD1/Maternity ward & 31 & 25.8 \\
\hline & - IPD2/Medical-Surgical & 18 & 15.0 \\
\hline & - ICU & 18 & 15.0 \\
\hline & - $\quad$ Specialist center & 4 & 3.3 \\
\hline & - $\quad$ A \& E / OPD & 15 & 12.5 \\
\hline & - Children center & 6 & 5.0 \\
\hline \multirow[t]{4}{*}{04} & Years of service & & \\
\hline & - $\quad$ Less than 2years & 20 & 16.7 \\
\hline & - 2 to 5 years & 54 & 45.0 \\
\hline & - $\quad$ More than 5 years & 46 & 38.3 \\
\hline
\end{tabular}




\subsection{Prevalence of Burnout Among Nurses}

To determine the prevalence of burnout, nurses were asked to fill out a questionnaire that had the MBI tool incorporated into it. Figure 2 below, shows that the prevalence of burnout within the MBI subscales was highest in the subscale of personal accomplishment (PA) - 72.5\%), followed by Depersonalization (DP) $-66.8 \%$ and Emotional Exhaustion (EE) - 61.7\%. Thus, the overall prevalence of burnout among nurses was $66.95 \%$.

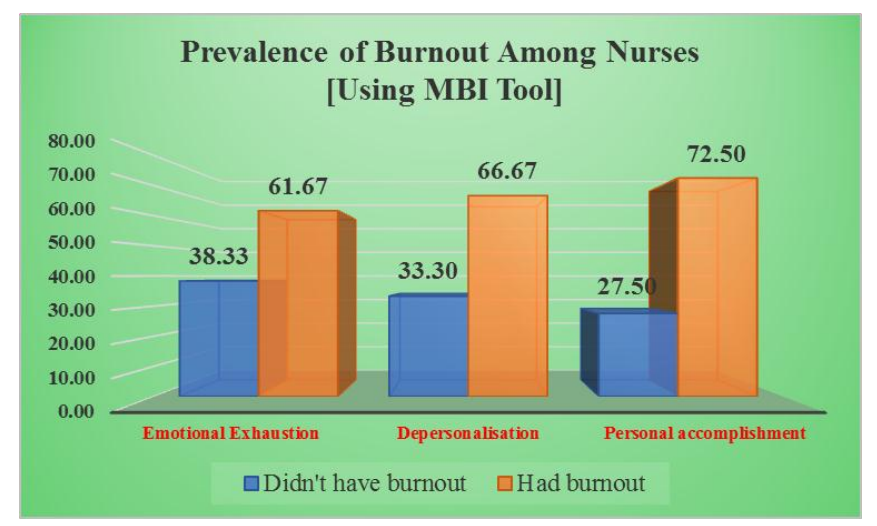

Figure 2. Prevalence of burnout among nurses [Using MBI subscales]

\subsection{Distribution of Personal Accomplishment Among Nurses With Burnout}

To determine the distribution of personal accomplishment of duties among nurses with burnout, the MBI scale was scored by calculating means of subscale. Based on the different dimensions of burnout (EE, DP \& PA) and using cut-off scores for the means, respondents were classified as 'High', 'Moderate' or 'Low' burnout cases/category on the respective subscales. High mean scores on EE and DP subscales corresponded to higher degrees of experiencing burnout, whereas a low mean score on the PA subscale corresponded to a higher degree of burnout. Individuals with burnout usually have a score of 27 and above in EE, 10 and above in DP, 40 and above in PA (Viva, et al., 2011).

The study found that nurses with high burnout had the lowest level of personal accomplishment at $18.33 \%$ while nurses with low burnout had the highest level of personal accomplishment (72.5\%). See Figure 3 below for details.

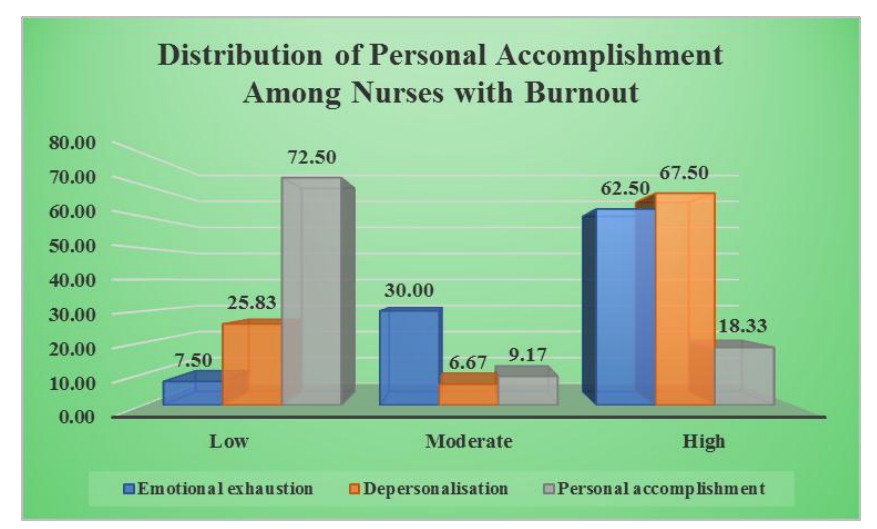

Figure 3. Distribution of personal accomplishment among nurses with burnout

The mean scores showed that, overall, among the nurses, EE was high 27.9 ( $\mathrm{SD} \pm 7.2$ ), DP was moderate 9.6 $(\mathrm{SD} \pm 4.2)$, and $\mathrm{PA}$ was moderate $39.7(\mathrm{SD} \pm 6.0)$. 
Table 5. Mean scores of the MBI sub-scale among nurses

\begin{tabular}{llll}
\hline Sub-scale & Mean & Range & Standard Deviation \\
\hline EE & 27.85 (High) & $10-44$ & 7.2 \\
\hline DP & 9.55 (Moderate) & $2-17$ & 4.2 \\
\hline PA & 39.68 (Moderate) & $20-54$ & 6.0 \\
\hline
\end{tabular}

EE=Emotional Exhaustion, DP=Depersonalization, $\mathrm{PA}=$ Personal Accomplishment

\subsection{Individual Factors Associated With Burnout Among Nurses at IHK}

The individual factors included; socio-demographics and job satisfaction. Bivariate analysis and cross tabulation were done to determine the individual factors associated with burnout among nurses. The results are shown in Table 6 below.

Table 6. Cross tabulation and bivariate analysis of individual factors associated with burnout

\begin{tabular}{|c|c|c|c|c|c|}
\hline \multirow[t]{2}{*}{ S. No } & \multirow[t]{2}{*}{ Variables } & \multicolumn{2}{|l|}{ Burnout } & \multirow{2}{*}{$\begin{array}{l}\text { Total } \\
(n=120)\end{array}$} & \multirow[t]{2}{*}{ Test Statistic } \\
\hline & & Yes & No & & \\
\hline \multirow[t]{4}{*}{01} & Age in years & & & & \\
\hline & - $\quad 18-25$ & $11(9.2 \%)$ & $0(0 \%)$ & 11 & $X^{2}=6.670$ \\
\hline & - $\quad 26-35$ & $70(58.3 \%)$ & $23(19.2 \%)$ & 93 & $\mathrm{df}=2$ \\
\hline & - 36-above & $9(7.5 \%)$ & $7(5.8 \%)$ & 16 & $p=0.036 *$ \\
\hline \multirow[t]{3}{*}{02} & Gender & & & & $X^{2}=2.695$ \\
\hline & - $\quad$ Male & $13(10.8 \%)$ & $1(0.8 \%)$ & 14 & $\mathrm{df}=1$ \\
\hline & - $\quad$ Female & $77(64.2 \%)$ & $29(24.2 \%)$ & 106 & $p=0.101$ \\
\hline \multirow[t]{9}{*}{03} & Departments & & & & \\
\hline & - $\quad$ Theatre & $13(10.8 \%)$ & $7(5.8 \%)$ & 20 & \\
\hline & - $\quad$ Pediatrics & $4(3.3 \%)$ & $4(3.3 \%)$ & 8 & \\
\hline & - $\quad$ IPD 1 & $26(21.7 \%)$ & $5(4.2 \%)$ & 31 & $X^{2}=12.716$ \\
\hline & - $\quad$ IPD 2 & $16(13.3 \%)$ & $2(1.7 \%)$ & 18 & $\mathrm{df}=7$ \\
\hline & - $\quad$ ICU & $14(11.7 \%)$ & $4(3.3 \%)$ & 18 & $p=0.079$ \\
\hline & - $\quad$ Specialist centre & $1(0.8 \%)$ & $3(2.5 \%)$ & 4 & \\
\hline & - $\quad$ A \& E / OPD & $12(10.0 \%)$ & $3(2.5 \%)$ & 15 & \\
\hline & - Children centre & $4(3.3 \%)$ & $2(1.7 \%)$ & 6 & \\
\hline \multirow[t]{4}{*}{04} & Years in service & & & & \\
\hline & - $\quad$ Less than 2years & $16(13.3 \%)$ & $4(3.3 \%)$ & 20 & $X^{2}=10.961$ \\
\hline & - 2-5years & $47(39.2 \%)$ & $7(5.8 \%)$ & 54 & $\mathrm{df}=2$ \\
\hline & - $\quad$ More than 5years & $27(22.5 \%)$ & $19(15.8 \%)$ & 46 & $p=0.004 * *$ \\
\hline \multirow[t]{3}{*}{05} & Job satisfaction & & & & $\mathrm{X}^{2}=4.361$ \\
\hline & - $\quad$ Yes, satisfied & $53(44.2 \%)$ & $24(20.0 \%)$ & 77 & $\mathrm{df}=1$ \\
\hline & - No, disssatisfied & $37(30.8 \%)$ & $6(5.0 \%)$ & 43 & $p=\mathbf{0 . 0 3 7} *$ \\
\hline
\end{tabular}

$\mathrm{X}^{2}=$ Pearson Chi Square, $\mathrm{df}=$ Degree of Freedom, $p=$ Probability Value

As shown in table 6 above, the study found that age of the respondents $\left(\mathrm{X}_{(2)}^{2}=6.670, p=0.036\right)$ was associated with burnout. Respondent years in service (experience) was even more highly associated with burnout of nurses $\left(\mathrm{X}_{(2)}^{2}=10.961, p=0.004\right)$. Similarly, job satisfaction $\left(\mathrm{X}^{2}{ }_{(1)}=4.361, p=0.037\right)$ was associated with burnout. 
Whereas $64.2 \%$ of female had burnout and most of the staffs (nurses) in different departments had burnout, there was no statistical significance.

\subsection{Organizational Factors Associated With Burnout Among Nurses}

The organizational factors included in the study were related to work load and creating a supportive environment for nurses.Bivariate analysis and cross tabulation were done to determine the organizational factors associated with burnout among nurses. The results are shown in Table 7 below.

Table 7. Cross tabulation and bivariate analysis of organizational factors associated with burnout

\begin{tabular}{|c|c|c|c|c|c|}
\hline \multirow{2}{*}{$\begin{array}{l}\text { S. } \\
\text { No }\end{array}$} & \multirow[t]{2}{*}{ Variables } & \multicolumn{2}{|l|}{ Burnout } & \multirow{2}{*}{$\begin{array}{l}\text { Total } \\
(n=120)\end{array}$} & \multirow[t]{2}{*}{ Test Statistic } \\
\hline & & Yes & No & & \\
\hline \multirow[t]{4}{*}{01} & Emotional Exhaustion (EE) & & & & \\
\hline & - $\quad \operatorname{Low}(0-18)$ & $0(0.0 \%)$ & $9(7.5 \%)$ & 9 & $X^{2}=29.197$ \\
\hline & - $\quad$ Moderate(19-26) & $29(24.2 \%)$ & $7(5.8 \%)$ & 36 & $\mathrm{df}=2$ \\
\hline & - $\operatorname{High}(\geq 27)$ & $61(50.8 \%)$ & $14(11.7 \%)$ & 75 & $p=0.000 * *$ \\
\hline \multirow[t]{4}{*}{$\mathbf{0 2}$} & Depersonalization (DP) & & & & \\
\hline & - $\quad$ Low $(0-5)$ & $86(71.7 \%)$ & $19(15.8 \%)$ & 105 & $\mathrm{X}^{2}=72.803$ \\
\hline & - $\quad$ Moderate (6-9) & $2(1.7 \%)$ & $6(5.0 \%)$ & 8 & $\mathrm{df}=2$ \\
\hline & - $\quad \operatorname{High}(\geq 10)$ & $2(1.7 \%)$ & $5(4.2 \%)$ & 7 & $p=\mathbf{0 . 0 0 0} * *$ \\
\hline \multirow[t]{4}{*}{$\mathbf{0 3}$} & Personal Accomplishment (PA) & & & & \\
\hline & - $\quad$ Low $(\geq 40)$ & $65(54.2 \%)$ & $22(18.3 \%)$ & 87 & $X^{2}=0.337$ \\
\hline & - $\quad$ Moderate (34-39) & $9(7.5 \%)$ & $2(1.7 \%)$ & 11 & $\mathrm{df}=2$ \\
\hline & - $\quad \operatorname{High}(0-33)$ & $16(13.3 \%)$ & $6(5.0 \%)$ & 22 & $p=0.845$ \\
\hline \multirow[t]{3}{*}{04} & Hours worked in a day & & & & $X^{2}=5.848$ \\
\hline & - $\quad 8$-12hours & $88(73.3 \%)$ & $26(21.7 \%)$ & 114 & $\mathrm{df}=1$ \\
\hline & - $\quad$ More than 12 hours & $2(1.7 \%)$ & $4(3.3 \%)$ & 6 & $p=0.016 *$ \\
\hline \multirow[t]{3}{*}{05} & Days worked per week & & & & $X^{2}=0.626$ \\
\hline & - 3-5days & $87(72.5 \%)$ & $28(23.3 \%)$ & 115 & $\mathrm{df}=1$ \\
\hline & - $\quad$ More than 5days & $3(2.5 \%)$ & $2(1.7 \%)$ & 5 & $p=0.429$ \\
\hline \multirow[t]{4}{*}{06} & Clients cared for in a day & & & & \\
\hline & - $\quad$ Less than 10 & $73(60.8 \%)$ & $25(20.8 \%)$ & 98 & $\mathrm{X}^{2}=0.088$ \\
\hline & - $\quad 10-20$ & $3(2.5 \%)$ & $1(0.8 \%)$ & 4 & $\mathrm{df}=2$ \\
\hline & - $\quad$ More than 20 & $14(11.7 \%)$ & $4(3.3 \%)$ & 18 & $p=0.957$ \\
\hline \multirow[t]{4}{*}{07} & Severity of patient problems & & & & \\
\hline & - $\quad$ Not severe & $28(23.3 \%)$ & $5(4.2 \%)$ & 33 & $\mathrm{X}^{2}=4.099$ \\
\hline & - $\quad$ Severe & $52(43.3 \%)$ & $18(15.0 \%)$ & 70 & $\mathrm{df}=2$ \\
\hline & - Very severe & $10(8.3 \%)$ & $7(5.8 \%)$ & 17 & $p=0.129$ \\
\hline \multirow[t]{4}{*}{08} & Work for available time & & & & \\
\hline & - Little work & $2(1.7 \%)$ & $0(0.0 \%)$ & 2 & $X^{2}=1.802$ \\
\hline & - $\quad$ Enough work & $43(35.8 \%)$ & $18(15.0 \%)$ & 61 & $\mathrm{df}=2$ \\
\hline & - $\quad$ Too much work & $45(37.5 \%)$ & $12(10.0 \%)$ & 57 & $p=0.406$ \\
\hline \multirow[t]{2}{*}{09} & Conflicting demands at work & & & & $\mathrm{X}^{2}=1.850$ \\
\hline & - $\quad$ Yes & $75(62.5 \%)$ & $28(23.3 \%)$ & 103 & $\mathrm{df}=1$ \\
\hline
\end{tabular}




\begin{tabular}{|c|c|c|c|c|c|}
\hline & - $\quad$ No & $15(12.5 \%)$ & $2(1.7 \%)$ & 17 & $p=0.174$ \\
\hline \multirow[t]{4}{*}{10} & Got information on job-well being & & & & \\
\hline & - $\quad$ Yes & & & & $X^{2}=0.074$ \\
\hline & - $\quad$ No & $73(60.8 \%)$ & $25(20.8 \%)$ & 98 & $\mathrm{df}=1$ \\
\hline & & $17(14.2 \%)$ & $5(4.2 \%)$ & 22 & $p=0.785$ \\
\hline \multirow[t]{3}{*}{11} & Got social support at work & & & & $X^{2}=6.667$ \\
\hline & - $\quad$ Yes & $48(40.0 \%)$ & $24(20.0 \%)$ & 72 & $\mathrm{df}=1$ \\
\hline & - $\quad$ No & $42(35.0 \%)$ & $6(5.0 \%$ & 48 & $p=0.010 * *$ \\
\hline \multirow[t]{3}{*}{12} & Got feedback for concern raised & & & & $\mathrm{X}^{2}=1.368$ \\
\hline & - $\quad$ Yes & $62(51.7 \%)$ & $24(20.0 \%)$ & 86 & $\mathrm{df}=1$ \\
\hline & - $\quad$ No & $28(23.3 \%)$ & $6(5.0 \%)$ & 34 & $p=0.242$ \\
\hline \multirow[t]{3}{*}{13} & Participation in decision making & $36(30.0 \%)$ & $16(13.3 \%)$ & 52 & $X^{2}=1.629$ \\
\hline & - $\quad$ Yes & $54(45.0 \%)$ & $14(11.7 \%)$ & 68 & $\mathrm{df}=1$ \\
\hline & - $\quad$ No & & & & $p=0.202$ \\
\hline
\end{tabular}

$\mathrm{X}^{2}=$ Pearson Chi Square, $\mathrm{df}=$ Degree of Freedom, $p=$ Probability Value

As shown in table 7 above, the study found that Emotional Exhaustion (EE) of the respondents $\left(\mathrm{X}^{2}{ }_{(2)}=29.197\right.$, $p=0.000$ ) was associated with burnout. Most of the nurses, 61(50.8\%) had EE and they had burnout. Depersonalization (DP) $\left(\mathrm{X}_{(2)}^{2}=72.803, p=0.000\right)$ was also associated with burnout among nurses. Again, hours worked in a day $\left(\mathrm{X}_{(1)}^{2}=72.803, p=0.016\right)$ by nurses was associated with burnout. Indeed, most of the respondents (73.3\%) who worked 8-12hours a day had burnout. Getting social support at work $\left(\mathrm{X}_{(1)}^{2}=72.803, p=0.016\right)$ was associated with burnout, thus $48(40.0 \%)$ of the nurses who got social support had burnout.

\section{Discussion of Results}

\subsection{Prevalence of Burnout}

The prevalence of burnout within the MBI subscales was as follows; Personal Accomplishment (PA)- 72.5\%), Depersonalization (DP) $-66.8 \%$ and Emotional Exhaustion (EE) - 61.7\%. Thus, the overall prevalence of burnout among nurses was $66.95 \%$. High level of emotional exhaustion (EE), high level of depersonalization (DP) and a reduced sense of personal accomplishment (PA) is typically characteristic of professionals with a high degree of burnout (Heeb \& Haberey-Knuessi, 2014).

This finding of this study is similar to many other studies. For example; according to Dubale, et al. (2019), the prevalence of burnout among physicians, nurses, and healthcare providers in Sub-Saharan Africa ranges from 40 to $80 \%$, with the highest levels being recorded among nurses. Another author asserted that the prevalence of burnout among nursing professionals is high (Guillermo, et al., 2015). A study done in Uganda established that $63.08 \%$ of nurses had high burnout (Martha, 2012).

Other studies, however, found slightly different results. For example; a systematic review and meta-analysis conducted to examine burnout symptoms prevalence in nurses worldwide showed that the overall prevalence of burnout symptoms among global nurses was $11.23 \%$. The highest burnout symptoms prevalence was in Sub-Saharan African region while Europe and Central Asia region had the lowest (Tiffany, 2019). Several reasons for the low incidence of burnout on nursing managers in Switzerland were realized (Heeb \& Haberey-Knuessi, 2014). These are; (1) cultural and contextual differences, which may explain the higher rates of burnout in North American managers as compared to nurses who tend to have lower scores on burnout in Europe (Schaufeli \& Dierendonck, 1995). (2) The low degree of burnout among Europeans might not be specific to managers and thus reflect a cross-national difference in the prevalence of burnout (Aiken, Sermeus, Van-Den, Heede, \& et al., 2012).

\subsection{Distribution of Personal Accomplishment Among Nurses With Burnout}

The study found that nurses with high burnout had the lowest level of personal accomplishment at $18.33 \%$ while nurses with low burnout had the highest level of personal accomplishment (72.5\%). In some studies, it was asserted that most of the variations regarding emotional exhaustion (EE) were due to pronounced differences 
related to work schedules, team size and congruence of personal and organizational values as well as conflicts within the team. On the other hand, sex and length of managerial experience were associated with depersonalization (DP) and overtime associated with personal accomplishment (PA) (Heeb \& Haberey-Knuessi, 2014).

\subsection{Individual Factors Associated With Burnout Among Nurses}

This study found that age of the respondents ( $p=0.036)$ was associated with burnout. Respondent years in service (experience) was even more highly associated with burnout of nurses $(p=0.004)$ as well as job satisfaction $(p=0.037)$. In a related study (Elbarazi, Loney, Yousef, \& Elias, 2017), gender, nationality, service duration, working hours, and shift patterns were all significantly associated with burnout. Staff nurses less than 30 years with high to very high neuroticism were more likely to experience high EE, high DP, and low PA (Ang, et al., 2016).

According to other scholars (Ang, et al., 2016), it was found that nurses who had diploma and advanced diploma education were more likely to experience high EE $(\mathrm{p}<0.01)$ and high DP $(\mathrm{p}<0.01)$. This was in comparison to nurses who only had vocational training, which is the base level to be credited as a registered nurse in Singapore. Nurses with bachelor or postgraduate degree qualifications were about 2 times less likely to have low PA $(\mathrm{OR}=$ $0.52 ; 95 \%$ CI: $0.40-0.68)$, compared to nurses with vocational training.

In yet another study, factors associated with higher rates of burnout on multivariable regression analyses included individual level factors: male gender $(p=0.007)$, marital status (widowed or divorced) $(p=0.011)$, depression $(\mathrm{p}=0.020)$, type $\mathrm{D}$ personality type $(\mathrm{p}=0.001)$, among others (Kim, et al., 2019).

\subsection{Organizational Factors Associated With Burnout Among Nurses}

This study found that Emotional Exhaustion (EE) of the respondents $(p=0.000)$, Depersonalization (DP) $(p=0.000)$, hours worked in a day $(p=0.016)$ by nurses and getting social support at work $(p=0.016)$ were associated with burnout.

Hence forth, it is likely that burnout might have multiple causes. Job satisfaction, job stress and vulnerable personality may be important factors associated with it (Hilde, et al., 2016). In another study, factors associated with higher rates of burnout on multivariable regression analyses included work related factors: working at a health center versus a rural hospital $(p=0.009)$; lack of a very supportive supervisor $(p=0.004)$, dissatisfaction with work/team interaction $(\mathrm{p}=0.007)$, and career dissatisfaction $(\mathrm{p}=0.020)$, among others were associated with burnout (Kim, et al., 2019).

\section{Conclusion}

The study showed that overall, among the nurses, EE was high, DP was moderate, and PA was moderate. Having no job satisfaction, no social support on the job and not taking part in decision making concerning their welfare were strongly associated with burnout.

\section{Acknowledgement}

The authors would wish to acknowledge the technical support of the staff of Faculty of Health Science _ Uganda Martyrs University, in this study. We remain indebted to all our research participants who offered the information.

\section{References}

Adamos-Konstantinos, K., Konstantinos, B., Maria, S., \& Vasileious, S. (2018). Burnout evaluation and potential predictors in a greek cohort of mental health nurses. Archives of Psychiatric Nursing, 32(7). https://doi.org/10.1016/j.apnu.2018.01.002

Aiken, L. H., Sermeus, W., Koen, V. D. H., et al.. (2012). Patient safety, satisfaction, and quality of hospital care: cross sectional surveys of nurses and patients in 12 countries in Europe and the United States. British Medical Journal, 344(7851). https://doi.org/10.1136/bmj.e1717

Ang, S. Y., Dhaliwal, S. S., Ayre, T. C., Uthaman, T., Fong, K. Y., Tien, C. E., et al.. (2016). Demographics and personality factors associated with burnout among Nurses in a Singapore tertiary hospital. BioMed Research International. https://doi.org/10.1155/2016/6960184

Anna, N., Anna, P., Agnieszka, G., \& Renata, W.-W. (2018). Selected socio-demographic and occupational factors of burnout syndrome in nurses employed in medical facilities in Malopolska-Preliminary results. Int $J$ Environ Res Public Health, 15(10), 2083. https://doi.org/10.3390/ijerph15102083 
Ashley, C. (2020). Simple random sampling [Online]. Retrieved from https://www.thoughtco.com/random-sampling-3026729

Attenello, F. J., Buchanan, I. A., Wen, T., Donoho, D. A., McCartney, S., Cen, S. Y., et al.. (2018). Factors associated with burnout among US neurosurgery. Journal of Neurosurgery, 129. https://doi.org/10.3171/2017.9.JNS17996

Elbarazi, I., Loney, T., Yousef, S., \& Elias, A. (2017). Prevalence of and factors associated with burnout among health care professionals in Arab countries: A systematic review. BMC Health Services Research, 17(491). https://doi.org/10.1186/s12913-017-2319-8

Heeb, J., \& Haberey-Knuessi, V. (2014). Health professionals facing burnout: What do we know about nursing managers?. Nursing Research and Practice, 2014(7). https://doi.org/10.1155/2014/681814

Jawad, F., Hayat, T., Zein, S., \& Christopher, M. (2016). Stress, burnout and coping strategies in preclinical medical students.

Jef, A., Veronique, D. G., \& Stan, M. (2015). Determinants and prevalence of burnout in emergency nurses: A systematic review of 25 years of research. International Journal of Nursing Studies, 52(2), 649-661. https://doi.org/10.1016/j.ijnurstu.2014.11.004

Kim, M. H., Mazenga, A. C., Yu, X., Simon, K., Nyasulu, P., Kazembe, P. N., et al.. (2019). Factors associated with burnout amongst healthcare workers providing HIV care in Malawi. Plos One, 14(9). https://doi.org/10.1371/journal.pone.0222638

Lusine, P., Sean, C., Mary, F., \& Linda, A. (2010). Nurse burnout and quality of care: Cross-national investigation in six countries. Research in Nursing and Health, 33(4), 288-298. https://doi.org/10.1002/nur.20383

Mansour, Z., Hamed, Y., Meisam, M., \& Mohammad, K. (2015). Level of workload and its relationship with job burnout among administrative staff. International Journal of Occupational Hygiene, 7, 53-60.

Marina, R., Patricia, O., Vanessa, B., Mercy, O., \& Olga, D. (2018). Prevalence and correlates of burnout in health $\begin{array}{lllll}\text { professionals in } & \text { Ecuador. }\end{array}$ https://doi.org/10.1016/j.comppsych.2017.11.011

Martha, N. (2012). Knowledge and perception toward professional burnout among nurses caring for patients with terminal illnesses. Hospice Africa Uganda and Uganda Cancer Institute.

Maslach, C., \& Leiter, M. P. (2016). Burnout. In G. Fink (Ed.), Handbook of stress: Vol. 1. Stress: Concepts, cognition, emotion, and behavior (pp. 351-357). Elsevier Academic Press. https://doi.org/10.1016/B978-0-12-800951-2.00044-3

Maslach, C., Jackson, S. E., \& Leiter, M. P. (1996). Maslach burnout inventory manual (3rd ed.). California, USA: Consulting Psychologists Press.

Natasha, K., Brian, O., Karl, P., \& Dragan, I. (2015). Work Related Stress, Burnout, Job Satisfaction and General Health of Nurses. Int J Environ Res Public Health, 12(1), 652-666. https://doi.org/10.3390/ijerph120100652

Nilgun, U., Mehmet, D., \& Ebru, C. (2015). The evaluation of burnout level among nurses giving care to postwar Syrian refugee patients. Acta Medica, 2015(4), 65-72.

Ozlem, A., Candan, O., Murat, B., Dijle, A., \& Merry, A. (2016). Job satisfaction and burnout among pediatric nurses. Journal of Nursing Management.

Philip, M., Eze, N., \& Johnbosco, C. (2018). Age and burnout syndrome in nursing professionals: moderating role of emotion-focused coping. Psychol Health Med, 24(1), 101-107. https://doi.org/10.1080/13548506.2018.1502457

Priscilla, H., David, P., \& Alberto, C. (2015). Burnout syndrome in hospital nurses. Management Faculty Research.

Schaufeli, W. B., \& Dierendonck, D. V. (1995). A cautionary note about the cross-national and clinical validity of cut-off points for the Maslach Burnout Inventory. Psychological Reports, 76(3). https://doi.org/10.2466/pr0.1995.76.3c.1083

Shin, Y., Satvinder, D., Tracy, C., Thendral, U., \& Kuan, Y. (2016). Demographics and personality factors associated with burnout among nurses in Singapore Tertiary hospital. Biomed Res Int, 2016(2016), 6960184. https://doi.org/10.1155/2016/6960184 
Tiffany, W. (2019, April). Global prevalence of burnout symptoms among nurses: A systematic review and meta-analysis. Journal of Psychiatric Research, 123, 9-20. https://doi.org/10.1016/j.jpsychires.2019.12.015

Unicef. (2018). Module 1: Understanding the Social Ecological Model (SEM) and Communication for Development (C4D).

Viva, C., Andra, T., \& Tarek, M. (2011). High rates of burnout among maternal health staff at a referral hospital in Malawi; A cross-sectional study. BMC Nursing, 10(9). https://doi.org/10.1186/1472-6955-10-9

Webster, M. (2019). Burnout definition; definition of burnout[Online]. Retrieved from https://www.merriam-webster.com/dictionary/burnout\#: :text=1\%20\%3A\%20the\%20cessation\%20of\%20o peration,burn\%20out

Wei, Y., Arul, E., \& Shu, Y. (2014). Prevalence of burnout among nurses in a community hospital in Singapore: A cross-sectional study. Proceedings of Singapore Healthcare.

Yamane, T. (1973). Statistics: an introduction analysis (3rd ed.). New York: Harper \& Row.

\section{Copyrights}

Copyright for this article is retained by the author(s), with first publication rights granted to the journal.

This is an open-access article distributed under the terms and conditions of the Creative Commons Attribution license (http://creativecommons.org/licenses/by/4.0/). 